\title{
Original Article (short paper) \\ Comparison of three criteria for overweight and obesity classification among adolescents from southern Brazil
}

\author{
Diego Augusto Santos Silva ${ }^{1 *}$, Priscila Custódio Martins ${ }^{1}$, Eliane Cristina de Andrade Gonçalves ${ }^{1}$ \\ ${ }^{1}$ Universidade Federal de Santa Catarina, UFSC, Florianópolis, SC, Brazil
}

\begin{abstract}
Aim: To estimate the prevalence of the classifications of overweight and obesity in adolescents according to three criteria for nutritional status classification (Conde \& Monteiro, International Obesity Task Force - IOTF and Word Health Organization - WHO), and to investigate whether sociodemographic factors associated with overweight and obesity differ among the three criteria. Method: cross-sectional study with 1,132 adolescents (14-19 years old) living in Brazil. Body Mass Index (BMI) was classified according to three criteria for nutritional status. A self-administered questionnaire was used to collect sociodemographic information. Sexual maturation was measured by self-reported Tanner stage ratings. Multinomial logistic regression was used to estimate the Odds Ratio and $95 \%$ confidence intervals. Results: The prevalence of the classification "overweight" (from here on referred to simply as "overweight") was $23.1 \%$ for WHO; $23.7 \%$ for Conde \& Monteiro criteria: and 19.2\% for IOTF. Both boys and girls aged 17-19 were more likely to be overweight using the WHO and Conde \& Monteiro criteria than those using the IOTF criteria. Girls in the postpubertal maturational stage were less likely of being overweight or obese using the three criteria. Conclusion: The three criteria result in different prevalence measures, with WHO and Conde and Monteiro criteria being more approximate in terms of prevalence and correlated factors when compared to IOTF criteria.
\end{abstract}

Keywords: body mass index, adolescent health, nutritional status, overweight.

\section{Introduction}

Since the 1980s, the prevalence of nutritional malnutrition has decreased and the prevalence of overweight and obesity in children and adolescents has increased, in Brazil ${ }^{1}$. These changes in weight status are mainly due to the implementation of public policies that have prioritized the decline of malnutrition, but the opposite situation (overweight) has become uncontrolled around the world ${ }^{1}$. In addition, the adoption of sedentary behaviors ${ }^{2}$ and physical inactivity are also factors associated with being overweight in the pediatric population ${ }^{3}$.

Being overweight leads to health hazards, such as respiratory failure, diabetes, hyperlipidemia, arterial hypertension and cardiac complications ${ }^{4}$. These diseases usually manifest in adulthood, but their onset begins at younger ages, especially in obese children and adolescents ${ }^{4}$. In this sense, the diagnoses of overweight and obesity in childhood or adolescence is of great relevance to the area of public health, since habits and lifestyle acquired in childhood and adolescence tend to remain in adult life ${ }^{5}$.

To estimate body fat accumulation, there are reference methods such as plethysmography and dual X-ray absorptiometry (DXA). However, these methods are costly and difficult to access ${ }^{6}$. Thus, anthropometric measures such as body mass, height, skinfolds and body perimeters are alternatives accessible to the population ${ }^{7}$. In this perspective, body mass index (BMI) has been a method used to assess weight status and health risk in children and adolescents ${ }^{8}$.

Some criteria have been proposed with the purpose of establishing BMI cutoff points for children and adolescents ${ }^{9,10,11}$. However, studies have pointed out differences in the prevalence of overweight and obesity among BMI classification criteria ${ }^{12,13,14,15}$. The Conde and Monteiro, WHO and IOTF criteria considered sex and age for the construction of cutoff points; however, they have been established based on data from different populations. Thus, sociocultural and economic aspects, such as lifestyle, income, and schooling may influence such differences in the prevalence of overweight ${ }^{16}$.

An international survey with 6,070 children and adolescents compared WHO and IOTF BMI classification criteria and found that the WHO criterion classified more overweight individuals when compared to the IOTF criterion. In addition, the WHO criteria presented greater sensitivity, while the IOTF criterion had higher specificity in the classification of overweight individuals ${ }^{15}$.

A study with Brazilian adolescents (11-17 years old), aimed at comparing three BMI reference criteria ${ }^{14}$, found higher prevalence of overweight using the Conde and Monteiro reference, followed by WHO and IOTF references. In addition, the factors that were associated with overweight were being male and the age group of 11 to $14^{14}$. Another study also found higher prevalence of overweight and obesity using the Conde and Monteiro cutoff points, followed by WHO and IOTF classification ${ }^{12}$.

The importance of this investigation should be highlighted, since most studies have investigated the prevalence of "overweight" (overweight and obesity) as a single weight status, grouping both categories (overweight + obesity $^{11,12}$ ), but it is necessary to investigate them separately because prevalence, associated factors, and agreement among methods can be differentiated between the classification of overweight and obese.

Based on the above, the aim of the study was to analyze the prevalence and sociodemographic factors associated with the statuses overweight and obese in adolescents from a city in southern Brazil according to three overweight criteria (WHO, Conde and Monteiro and IOTF). 


\section{Methods}

This study is characterized as school-based and cross-sectional and was approved by the Ethics Committee for Research with Human Beings of the Federal University of Santa Catarina (No. 746.536 of 2014) and developed between August and November 2014. The research was conducted in accordance with the Helsinki Declaration.

The population $(\mathrm{n}=5,182)$ was composed of adolescents aged 14-19 enrolled in state public schools in the city of São José, which has 209,804 inhabitants and a Municipal Human Development Index of $0.809^{17}$. São José has territorial boundaries with Florianópolis and they together form the most populous metropolitan region of Santa Catarina, Brazil.

The sampling process was determined in two stages: 1) stratified by state public high schools $(\mathrm{n}=11) ; 2$ ) classes clustered considering study shift and school grade $(\mathrm{n}=170$ classes). In stage two, all high school students who were present in the classroom on the days of data collection were invited to participate in the study.

For the sample calculation, unknown prevalence for the outcome $(50 \%)$, tolerable error of five percentage points, $95 \%$ confidence level and delineation effect of 1.5 were adopted, adding 20\% for losses and refusals, plus 20\% for association study. A sample of 751 adolescents was estimated. However, due to conglomerate sampling, all students in the classes were invited to participate in the survey, resulting in 1,132 students.

Students were defined as eligible if they were enrolled in the state education network, in the classroom on the day of data collection and between 14 and 19 years old. Adolescents who did not want to participate in the study were considered refusals and those with incomplete questionnaires or who did not perform one or more physical test were considered sample losses.

\section{Dependent variable}

BMI was the dependent variable and to calculate this index (body mass / height ${ }^{2}$ ), height was collected by means of Sanny ${ }^{\circledR}$ stadiometer with tripod (São Paulo, Brazil) and body mass with G-tech ${ }^{\circledR}$ digital scale (Zhongshan, China), according to the standardization of the International Society for the Advancement of Kinanthropometry (ISAK) ${ }^{18}$. Anthropometric measurements were obtained by a single evaluator with level 1 ISAK certification. The evaluator was trained before field work.

BMI was categorized as low weight, normal weight, overweight and obese according to cutoff points of the International Obesity Task Force (IOTF) ${ }^{8}$, Conde and Monteiro ${ }^{10}$, and the World Health Organization (WHO $)^{11}$. Cutoff points vary according to the age and sex of adolescents.

\section{Independent variables}

The independent variables were age, which was categorized as 14-16 and 17-19; economical level; and sexual maturation. The present study did not make the instruments reproducible in the this sample. However, all instruments are valid for their given purpose. Economic level was identified through the questionnaire of the Brazilian Association of Research Companies ${ }^{19}$, which divides the population into five categories in decreasing order of purchasing power (“A1", "A2", "B1", "B2" "C1", "C2", "D" and "E"). Due to the low frequency of adolescents in extreme categories ("A1": 0.0\%; "A2": 4.1\%; "B1": 20.9\%; "B2": 44.6\%; "C1": 24.5\%; "C2": 5.3\%; "D": 0.6\%; "E": 0.0\%), this variable was dichotomized into high level ("A1", "A2",,B1",,B2”) and low level ("C1",,C2",'D”,'E”). Sexual maturation was selfassessed by adolescents, according to criteria proposed by Tanner $(1962)^{20}$, validated and reproducible in the Brazilian population, with $r$ values of $0.71^{21}$. Stages were determined by self-assessment (figures) of breast development (girls) and genitals (boys), after individual and previous explanation of the instrument by the researcher, always of the same sex as the adolescent. This variable was classified as "Pre-pubertal / pubertal" and "Post-pubertal", because the frequency of pre-pubertal adolescents was low.

\section{Statistical analysis}

Descriptive statistics (mean, standard deviation, absolute and relative frequency) was used for sample characterization. The Mann Whitney U test was used to compare values of continuous variables according to sex, since none of the variables had normal distribution according to normality histograms.

The heterogeneity Chi-square test was used to verify whether or not there was a statistical difference in the weight status distribution according to independent variables. This information was run in each of the weight status distributions, according to IOTF, Conde and Monteiro and WHO cutoff points.

Multinomial logistic regression (reference category $=$ normal weight) was used to estimate odds ratios and $95 \%$ confidence intervals were used in order to verify association between weight status and independent variables. Different models were used according to the cut-off point for BMI (IOTF, Conde and Monteiro and WHO). The crude and adjusted analyses were used. In the adjusted analysis, all independent variables were inserted into the model, regardless of their $\mathrm{p}$ value in the crude analysis. Variables with $\mathrm{p}$ value $<0.05$ were considered associated with the outcome. Analyses were performed with the total sample and stratified by sex using the SPPSS software version 22.0.

\section{Results}

Overall, 1,132 adolescents (mean age $16.2 \pm 1.14$ ) participated in the study. Boys had higher mean values for the variables age, body mass and height when compared to girls. The majority of the sample was female (54.2\%), aged between 14 and 16 years $(59.8 \%)$ and were from a high economic level (69.5\%). A small part of the sample $(n=124)$ had no body mass and height values, therefore, BMI was not possible to obtain.

The prevalence of overweight in males was $17.7 \%, 21.6 \%$ and $12.5 \%$ for cutoff points suggested by WHO, Conde and Monteiro and IOTF, respectively. The prevalence of obesity was 
$5.2 \%, 5.0 \%$ and $14.4 \%$ for cutoff points suggested by WHO, Conde and Monteiro and IOTF, respectively (Table 1).

For BMI cutoff points suggested by WHO and Conde and Monteiro, boys aged 14-16 years had higher prevalence of overweight compared to boys aged 17-19. For cutoff points suggested by IOTF, boys at the pre-pubertal / pubertal maturational stage presented higher prevalence of overweight compared to those at the post-pubertal stage (Table 1).

Table 1. Sample distribution in relation to sociodemographic factors associated with nutritional status classification according to three different criteria for boys ( $n=519$, São José, Santa Catarina, Brazil

\begin{tabular}{|c|c|c|c|c|c|}
\hline \multirow[b]{2}{*}{ Variables } & \multicolumn{4}{|c|}{ Boys } & \multirow[b]{2}{*}{$\mathbf{p}$} \\
\hline & $\begin{array}{c}\text { Low weight } \\
\text { n (\%) }\end{array}$ & $\begin{array}{c}\text { Normal weight } \\
\text { n (\%) }\end{array}$ & $\begin{array}{c}\text { Overweight } \\
\text { n (\%) }\end{array}$ & $\begin{array}{c}\text { Obesity } \\
\text { n (\%) }\end{array}$ & \\
\hline \multicolumn{6}{|c|}{ WHO } \\
\hline Total & $15(2.9)$ & $339(65.3)$ & $02(17.7)$ & $27(5.2)$ & \\
\hline Age & & & & & $<0.01 *$ \\
\hline $14-16$ years & $07(2.6)$ & 178 (66.9) & $65(24.4)$ & $16(6.0)$ & \\
\hline $17-19$ years & $08(3.9)$ & $161(77.8)$ & $27(13.0)$ & $11(5.3)$ & \\
\hline Economic level & & & & & 0.24 \\
\hline High & $11(3.8)$ & 205 (71.7) & $58(20.3)$ & $12(4.2)$ & \\
\hline Low & $01(1.0)$ & $77(74.0)$ & $18(17.3)$ & $08(7.7)$ & \\
\hline Sexual maturation & & & & & 0.23 \\
\hline Pre-pubertal/ pubertal & $14(4.1)$ & $244(70.9)$ & $64(18.6)$ & $22(6.4)$ & \\
\hline Post- pubertal & $01(0.8)$ & $92(74.8)$ & $25(20.3)$ & $05(4.1)$ & \\
\hline \multicolumn{6}{|c|}{ Conde and Monteiro } \\
\hline Total & $03(0.6)$ & $332(64.0)$ & $112(21.6)$ & $26(5.0)$ & \\
\hline Age & & & & & $<0.01 \dagger$ \\
\hline $14-16$ years & $02(0.8)$ & $172(64.7)$ & $77(28.9)$ & $15(5.6)$ & \\
\hline $17-19$ years & $01(0.5)$ & $160(77.3)$ & $35(16.9)$ & $11(5.3)$ & \\
\hline Economic level & & & & & 0.34 \\
\hline High & $01(0.3)$ & $207(72.4)$ & $68(23.1)$ & $12(4.2)$ & \\
\hline Low & $01(1.0)$ & $74(71.2)$ & $21(20.2)$ & $08(7.7)$ & \\
\hline Sexual maturation & & & & & 0.53 \\
\hline Pre-pubertal/ pubertal & $03(0.9)$ & $243(70.6)$ & $77(22.4)$ & $21(6.1)$ & \\
\hline Post- pubertal & $00(0.0)$ & $86(69.9)$ & $32(26.0)$ & $05(4.7)$ & \\
\hline \multicolumn{6}{|c|}{ IOTF } \\
\hline Total & $37(7.1)$ & $346(66.7)$ & $67(12.5)$ & $23(14.4)$ & \\
\hline Age & & & & & 0.07 \\
\hline $14-16$ years & $14(5.3)$ & $196(73.7)$ & $43(16.2)$ & $13(4.9)$ & \\
\hline $17-19$ years & $23(11.1)$ & $150(72.5)$ & $24(11.6)$ & $10(4.8)$ & \\
\hline Economic level & & & & & 0.39 \\
\hline High & $20(7.0)$ & $218(76.2)$ & $38(13.3)$ & $10(3.5)$ & \\
\hline Low & $07(6.7)$ & $76(73.1)$ & $13(12.5)$ & $08(7.7)$ & \\
\hline Sexual maturation & & & & & $<0.05^{*}$ \\
\hline Pre-pubertal/ pubertal & $35(10.2)$ & $239(69.5)$ & $52(15.1)$ & $18(5.2)$ & \\
\hline Post- pubertal & $02(1.6)$ & $104(84.6)$ & $12(9.8)$ & $05(4.1)$ & \\
\hline
\end{tabular}

WHO: World Health Organization. IOTF: International Obesity Task Force. * Chi-square and Fisher's exact test $\uparrow(\mathrm{p}<0.05)$. 
The prevalence of overweight among girls was $16.3 \%$, $14.7 \%$ and $14.7 \%$ for cutoff points suggested by WHO, Conde and Monteiro and IOTF, respectively. The prevalence of obesity was $7.5 \%, 7.0 \%$ and $6.5 \%$ for cutoff points suggested by WHO, Conde and Monteiro and IOTF, respectively (Table 2).

For girls, when considering the three criteria for nutritional status classification, those in the post-pubertal stage of sexual maturation had higher prevalence of overweight and obesity than girls in the pre-pubertal / pubertal stage (Table 2).

In boys, the adjusted multinomial regression analysis revealed a similarity in the factors associated with overweight between cutoff points proposed by WHO and Conde and Monteiro. These results indicated that boys in the age group of 17 to 19 were more likely to be overweight (Table 3). For obesity, no investigated factor was associated.

Table 2. Sample distribution in relation to sociodemographic factors associated with nutritional status classification according to three different criteria for girls ( $\mathrm{n}=613$, São José, Santa Catarina, Brazil).

\begin{tabular}{|c|c|c|c|c|c|}
\hline \multirow[b]{2}{*}{ Variables } & \multicolumn{4}{|c|}{ Girls } & \multirow[b]{2}{*}{$\mathbf{p}$} \\
\hline & $\begin{array}{c}\text { Low weight } \\
\text { n (\%) }\end{array}$ & $\begin{array}{c}\text { Normal weight } \\
\text { n (\%) }\end{array}$ & $\begin{array}{c}\text { Overweight } \\
\text { n (\%) }\end{array}$ & $\begin{array}{c}\text { Obesity } \\
\text { n (\%) }\end{array}$ & \\
\hline \multicolumn{6}{|c|}{ WHO } \\
\hline Total & $01(0.2)$ & $388(63.3)$ & $100(16.3)$ & $46(7.5)$ & \\
\hline Age & & & & & 0.15 \\
\hline $14-16$ years & $00(0.0)$ & $225(70.3)$ & $68(21.2)$ & $27(8.4)$ & \\
\hline $17-19$ years & $01(0.5)$ & $163(75.8)$ & $32(14.9)$ & $19(8.8)$ & \\
\hline Economic level & & & & & 0.63 \\
\hline High & $00(0.0)$ & $212(71.6)$ & $56(18.9)$ & $28(9.5)$ & \\
\hline Low & $01(0.6)$ & $117(71.8)$ & $32(19.6)$ & $13(8.0)$ & \\
\hline Sexual maturation & & & & & $<0.01 \uparrow$ \\
\hline Pre-pubertal/ pubertal & $01(0.3)$ & $296(80.2)$ & $52(14.1)$ & $20(5.4)$ & \\
\hline Post- pubertal & $00(0.0)$ & $89(74.8)$ & $48(29.4)$ & $26(16.0)$ & \\
\hline \multicolumn{6}{|c|}{ Conde and Monteiro } \\
\hline Total & $10(1.6)$ & $392(63.9)$ & $90(14.7)$ & $43(7.0)$ & \\
\hline Age & & & & & 0.07 \\
\hline $14-16$ years & $03(0.9)$ & $230(71.9)$ & $62(19.4)$ & $25(7.8)$ & \\
\hline $17-19$ years & $07(3.3)$ & $162(75.3)$ & $28(13.0)$ & $01(8.4)$ & \\
\hline Economic level & & & & & 0.92 \\
\hline High & $06(2.3)$ & $215(72.6)$ & $49(16.6)$ & $16(8.8)$ & \\
\hline Low & $04(2.5)$ & $118(72.4)$ & $29(17.8)$ & $12(7.4)$ & \\
\hline \multicolumn{6}{|l|}{ Sexual maturation } \\
\hline Pre-pubertal/ pubertal & $10(2.7)$ & 295 (79.9) & $47(22.7)$ & $17(14.6)$ & $<0.01 \uparrow$ \\
\hline Post- pubertal & $00(0.0)$ & $94(57.7)$ & $43(26.4)$ & $26(26.0)$ & \\
\hline \multicolumn{6}{|c|}{ IOTF } \\
\hline Total & $41(6.7)$ & $364(59.4)$ & $90(14.7)$ & $40(6.5)$ & \\
\hline Age & & & & & 0.39 \\
\hline $14-16$ years & $20(6.2)$ & $219(68.4)$ & $58(18.1)$ & $23(7.2)$ & \\
\hline $17-19$ years & $21(9.80)$ & $145(67.4)$ & $32(14.9)$ & $17(7.9)$ & \\
\hline Economic level & & & & & 0.90 \\
\hline High & $23(7.8)$ & 201 (67.9) & $48(16.2)$ & $24(8.1)$ & \\
\hline Low & $14(8.6)$ & 107 (65.6) & $30(18.4)$ & $12(7.4)$ & \\
\hline
\end{tabular}


Pre-pubertal/ pubertal

$\begin{array}{cc}37(10.0) & 270(73.2) \\ 04(2.5) & 91(55.8)\end{array}$

48 (13.0)

$14(3.8)$

Post- pubertal

$04(2.5)$

$42(25.8)$

$26(16.0)$

WHO: World Health Organization. IOTF: International Obesity Task Force. ${ }^{*}$ Chi-square and Fisher’s exact test $\dagger(\mathrm{p}<0.05)$

Table 3. Adjusted multinomial regression analysis between socio-demographic factors, sexual maturation and overweight and obesity according to the three classification criteria for boys ( $\mathrm{n}=519$, São José, Santa Catarina, Brazil).

\begin{tabular}{|c|c|c|c|c|}
\hline \multirow{3}{*}{ Variables } & \multicolumn{4}{|c|}{ Boys } \\
\hline & \multicolumn{2}{|c|}{$\begin{array}{c}\text { Overweight } \\
\text { Adjusted analysis * }\end{array}$} & \multicolumn{2}{|c|}{$\begin{array}{c}\text { Obesity } \\
\text { Adjusted analysis * }\end{array}$} \\
\hline & OR & CI 95\% & OR & CI 95\% \\
\hline \multicolumn{5}{|c|}{ WHO } \\
\hline \multicolumn{5}{|l|}{ Age } \\
\hline $14-16$ years & 1 & & 1 & \\
\hline $17-19$ years & 2.55 & $(1.49-4.34) \dagger$ & 1.54 & $(0.67-3.52)$ \\
\hline \multicolumn{5}{|l|}{ Economic level } \\
\hline High & 1 & & 1 & \\
\hline Low & 1.12 & $(0.59-2.12)$ & 0.53 & $(0.20-1.38)$ \\
\hline \multicolumn{5}{|l|}{ Sexual maturation } \\
\hline Pre-pubertal/ pubertal & 1 & & 1 & \\
\hline Post- pubertal & 0.93 & $(0.54-1.60)$ & 2.16 & $(0.72-6.49)$ \\
\hline
\end{tabular}

Conde and Monteiro

Age

$14-16$ years

1

2.10

1

1.07

(0.61-1.90)

0.5

.32

(0.59-2.97)

Economic level

High

Low

Sexual maturation

Pre-pubertal/ pubertal

1

Post- pubertal

0.88

(0.54-1.43)

1.50

(0.55-4.12)

\section{IOTF}

\section{Age}

$14-16$ years

$17-19$ years

1.48

(0.76-2.86)

1.01

$(0.37-2.72)$

Economic level

High

$$
1
$$

1.10

$(0.52-2.30)$

0.41

$(0.15-1.11)$

\section{Sexual maturation}

Pre-pubertal/ pubertal

1

Post- pubertal 1.69

(0.86-3.33)

WHO: World Health Organization. IOTF: International Obesity Task Force; OR: odds ratio; CI: Confidence interval. * Analysis adjusted for all variables; $\uparrow \mathrm{p}<0.05$. 
In girls, the adjusted multinomial regression analysis revealed a similarity in the factors associated with overweight between cutoff points proposed by WHO and Conde and Monteiro, with girls aged 17-19 being more likely to have this condition. For obesity, associated factors were similar among the three classification criteria, and girls in the postpubertal maturation stage were more likely to have this condition (Table 4).

Table 4. Multinomial regression analysis adjusted between socio-demographic factors, sexual maturation and overweight and obesity according to the three classification criteria for girls ( $\mathrm{n}=613$, São José, Santa Catarina, Brazil).

\begin{tabular}{|c|c|c|c|c|}
\hline \multirow{3}{*}{ Variables } & \multicolumn{4}{|c|}{ Girls } \\
\hline & \multicolumn{2}{|c|}{$\begin{array}{c}\text { Overweight } \\
\text { Adjusted analysis * }\end{array}$} & \multicolumn{2}{|c|}{$\begin{array}{c}\text { Obesity } \\
\text { Adjusted analysis * }\end{array}$} \\
\hline & OR & CI 95\% & OR & CI 95\% \\
\hline \multicolumn{5}{|c|}{ WHO } \\
\hline \multicolumn{5}{|l|}{ Age } \\
\hline $14-16$ years & 1 & & 1 & \\
\hline $17-19$ years & 1.67 & $(1.03-2.71) \dagger$ & 1.15 & $(0.60-2.17)$ \\
\hline \multicolumn{5}{|l|}{ Economic level } \\
\hline High & 1 & & 1 & \\
\hline Low & 0.87 & $(0.52-1.46)$ & 1.09 & $(0.53-2.23)$ \\
\hline \multicolumn{5}{|l|}{ Sexual maturation } \\
\hline Pre-pubertal/ pubertal & 1 & & 1 & \\
\hline Post- pubertal & 0.31 & $(0.19-0.49) \dagger$ & 0.22 & $(0.12-0.43) \dagger$ \\
\hline \multicolumn{5}{|c|}{ Conde and Monteiro } \\
\hline \multicolumn{5}{|l|}{ Age } \\
\hline $14-16$ years & 1 & & 1 & \\
\hline $17-19$ years & 1.75 & $(1.05-2.92) \dagger$ & 1.04 & $(0.54-1.99)$ \\
\hline \multicolumn{5}{|l|}{ Economic level } \\
\hline High & 1 & & 1 & \\
\hline Low & 0.85 & $(0.49-1.45)$ & 1.00 & $(0.48-2.06)$ \\
\hline \multicolumn{5}{|l|}{ Sexual maturation } \\
\hline Pre-pubertal/ pubertal & 1 & & 1 & \\
\hline Post- pubertal & 0.32 & $(0.20-0.53) \dagger$ & 0.22 & $(0.11-0.42) \dagger$ \\
\hline \multicolumn{5}{|c|}{ IOTF } \\
\hline \multicolumn{5}{|l|}{ Age } \\
\hline $14-16$ years & 1 & & 1 & \\
\hline $17-19$ years & 1.14 & $(0.67-1.95)$ & 1.01 & $(0.49-2.10)$ \\
\hline \multicolumn{5}{|l|}{ Economic level } \\
\hline High & 1 & & 1 & \\
\hline Low & 0.78 & $(0.46-1.32)$ & 0.96 & $(0.45-2.04)$ \\
\hline \multicolumn{5}{|l|}{ Sexual maturation } \\
\hline Pre-pubertal/ pubertal & 1 & & 1 & \\
\hline Post- pubertal & 0.31 & $(0.18-0.52) \dagger$ & 0.17 & $(0.08-0.36) \dagger$ \\
\hline
\end{tabular}

WHO: World Health Organization. IOTF: International Obesity Task Force; OR: odds ratio; CI: Confidence interval. * Analysis adjusted for all variables; $\uparrow \mathrm{p}<0.05$. 


\section{Discussion}

The results showed a greater concordance in the prevalence of overweight and obesity between WHO and Conde and Monteiro criteria and showed a slight increase in the prevalence of overweight (overweight + obesity) when considering the cutoffs of Conde and Monteiro (23, 7\%) compared to WHO $(23.1 \%)$ and IOTF (19.2\%). These differences in the prevalence of overweight and obesity among the three different BMI classification criteria have also been reported in other studies ${ }^{14,15}$. A study carried out with 7 to 15 year-old schoolchildren from Rio Grande do Sul, Brazil, found that the prevalence of overweight and obesity was higher in comparison to WHO and IOTF criteria ${ }^{13}$.

The study by Pelegrini, Silva, Gaya, Petroski ${ }^{14}$ with adolescents aged 11-17 from all geographic regions of Brazil found a prevalence of overweight (overweight + obesity) of $20.6 \%$ according to the criteria of Conde and Monteiro; $20.1 \%$ for the WHO criteria; and $15.3 \%$ for the IOTF criteria ${ }^{14}$. The authors also observed greater agreement between cutoff points of Conde and Monteiro and $\mathrm{WHO}^{14}$. A possible explanation for the higher prevalence of overweight and obesity found using the BMI classification criteria proposed by Conde and Monteiro is the fact that this reference was constructed using data of Brazilian children and adolescents, revealing the high prevalence of excess weight in this population. In Brazil, the process of nutritional transition, characterized by a decline in the prevalence of nutritional malnutrition and an increase in the prevalence of overweight and obesity ${ }^{1}$, has been changing the weight status scenario.

According to the WHO and Conde and Monteiro cutoff points, boys had higher overweight values compared to girls. However, when considering only obesity, girls presented higher prevalence values compared to boys. In turn, according to the IOTF cutoff points, boys presented lower prevalence of overweight and higher prevalence of obesity than girls. These differences among classification criteria can be explained by the sociocultural differences of each population in relation to the cutoff point, since IOTF criteria used a population of six countries: Brazil, Hong Kong, England, the Netherlands, Singapore and the United States ${ }^{9}$. The WHO classification was developed from data of American adolescents in the age group of 5 to 19 years of age ${ }^{11}$. The Conde and Monteiro criteria were constructed from data of Brazilian adolescents (2-19 years old $)^{10}$. Lifestyle, economic level and sexual maturation are factors that differentiate populations of each country and that may influence the growth curves and, consequently, the cutoff points for $\mathrm{BMI}^{7}$.

Boys and girls aged 17-19 were more likely to be overweight, according to WHO and Conde and Monteiro classification. Pelegrini, Silva, Gaya, Petroski ${ }^{14}$ observed that boys and adolescents aged 11-12 and 13-14 years old were more likely to be overweight and obese in the three BMI classification criteria when compared to adolescents aged 15-17 ${ }^{14}$. Physical inactivity and the adoption of sedentary behaviors are factors associated with higher prevalence of overweight ${ }^{21}$. Physical activity practices tend to decrease with age; in addition, factors such as entry into the labor market, many hours of study and lower participation of parents in school are factors associated with lower levels of physical activity and, consequently, increased prevalence of overweight in older adolescents ${ }^{22}$

Girls in the post-pubertal maturational stage were less likely to be overweight and obese according to the three classification criteria. This can be explained by changes in body composition, such as increased fat deposits in adolescents, especially in the pubertal maturational stage, which may lead to changes in body mass $^{23}$. In addition, growth spurts, an increase and distribution of adipose tissue in certain parts of the body, an increase of subcutaneous fat and of leptin concentrations, responsible for body weight and energy balance regulation, are changes that occur during puberty ${ }^{23}$.

One of the limitations of this study is related to the collection of information through self-administered questionnaire, since there is the possibility of response bias for the identification of some variables, such as the economic level. In addition, adolescents aged 10-13 were not investigated, which is a period of great changes in sexual maturation, such as puberty. However, sexual maturation was one of the variables collected and used in multivariate models. The cross-sectional design of the study is also a limitation because it doesn't permit the establishment of causal relations between the dependent variable and the independent variables.

Among the strengths of this study, the sample representativeness stands out, as it permitted inferences to be maderegarding schoolchildren from other municipalities with characteristics similar to the sample of this study. The information presented is useful for the public health area regarding which criteria have the greatest agreement, considering the importance of the diagnosis of overweight and obese in Brazilian adolescents for the prevention of diseases associated with this condition. The results found in the present study could be used by health professionals in choosing the method of classification of BMI most appropriate for the population under investigation. In addition, it may prioritize the subgroups of adolescents most affected by overweight in lifestyle change strategies.

It was concluded that the three criteria for BMI classification investigated showed different results, with WHO and Conde and Monteiro criteria being more approximate in terms of prevalence and correlated factors when compared to IOTF criteria. According to WHO and Conde and Monteiro cutoff points, the factor associated with overweight in males and females was the age group of 17 to 19 years. According to WHO, Conde and Monteiro and IOTF cutoff points, girls in the post-pubertal stage were less likely to be overweight or obese.

\section{References}

1. Silva DAS. Sobrepeso e obesidade em crianças de cinco a dez anos de idade beneficiárias do Programa Bolsa Família no estado de Sergipe, Brasil. Rev Paul Pediatr. 2011; 29(4):529-3Hind K. Sedentary Time and Central Adiposity in Children. J Clin Densitom. 2016; 19(3):264-265.

2. Onis MD. Prevenção do sobrepeso e da obesidade infantis. J Peatr. 2015;9(2):105-7. 
3. Eckel N, Meidtner K, Kalle-Uhlmann T, Stefan N, Schulze MB. Metabolically healthy obesity and cardiovascular events: A systematic review and meta-analysis. Eur J Prev Cardiol. 2016;23(9):56-66.

4. Ahrens W, Pigeot I, Pohlabeln H, De Henauw S, Lissner L, Molnár D, et al. Prevalence of overweight and obesity in European children below the age of 10. Int J Obes. 2014;38(2):99-107.

5. Feferbaum R, Leone C, Casanova NR, Neri CP, Blanco CE, Allende SMA. 10-month anthropometric and bioimpedance evaluation of a nutritional education program for 7-to 14-yearold students. Rev Bras Cineantropom Desempenho Hum. 2012;22(3):283-290.

6. Burgos MS, Burgos LT, Camargo MD, Franke SIR, Prá D, Silva AMV. Relationship between anthropometric measures and cardiovascular risk factors in children and adolescents. Arq Bras Cardiol. 2013;101(4):288-296.

7. Cole TJ, Lobstein T. Extended international (IOTF) body mass index cut offs for thinness, overweight and obesity. Pediatr Obes. 2012;7(4):284-294.

8. Cole TJ, Bellizzi MC, Flegal KM, Dietz WH. Establishing a standard definition for child overweight and obesity worldwide: international survey. Bmj. 2000;320(7244):1240-1246.

9. Conde WL, Monteiro CA. Body mass index cutoff points for evaluation of nutritional status in Brazilian children and adolescents. J Peatr. 2006;82(4):266-272.

10. Onis MD, Onyango AW, Borghi E, Siyam A, Nishida C, Siekmann J. Development of a WHO growth reference for school-aged children and adolescents. Bull World Health Organ. 2007;85(9):660-667.

11. Clemente APG, Santos CDL, Benedito-Silva AA, Sawaya, AL. Índice de massa corporal de adolescentes: comparação entre diferentes referências. Rev Paul Pediatr. 2011;29(2):171-7.

12. Dumith SC, Farias Júnior JC. Sobrepeso e obesidade em crianças e adolescentes: comparação de três critérios de classificação baseados no índice de massa corporal. Rev Panam Salud Publica. 2010;28(1):30-35.

13. Pelegrini A, Silva DAS, Gaya ACA, Petroski, EL. Comparison of three criteria for oveweight and obesity classification in Brazilian adolescents. Nutr J. 2013;12(1):5-13.

14. Valerio G, Balsamo A, Baroni MG, Brufani C, Forziato C, Grugni $\mathrm{G}$, et al. Childhood obesity classification systems and cardiometabolic risk factors: a comparison of the Italian, World Health
Organization and International Obesity Task Force references. Ital J Ped. 2017;43(1):19

15. Lee RL, Lee PH, Sze DM, Chien WT. Anthropometric profile of Hong Kong children and adolescents: the Wellness Population of Youth Study. JASH In press 2017.

16. Atlas Brasil [página na Internet]. Atlas de Desenvolvimento Humano do Brasil, 2013 [acessado em 10 de fevereiro de 2017]. Disponível em: http://www.atlasbrasil.org.br/2013/.

17. Marfell-Jones M, Olds T, StewartA, Carter J. ISAK: Potchefstroom: International Standards for Anthropometric Assessment. 2006.

18. Brasil - Associação Brasileira de Empresas de Pesquisa. Critério de classificação econômica brasil. São paulo: ABEP 2010.

19. Tanner JM. Growth at adolescence; with a general consideration of the effects of hereditary and environmental factors upon growth and maturation from birth to maturity. Oxford: Blackwell Scientific; 1962.

20. Matsudo SMM, Matsudo VKR. Validade da autoavaliação na determinação da maturação sexual. RBCM. 1991;5(2):18-35.

21. Ekelund U, Luan JA, Sherar LB, Esliger DW, Griew P, Cooper A, et al. Moderate to vigorous physical activity and sedentary time and cardiometabolic risk factors in children and adolescents. JAMA. 2012;307(7):704-712.

22. Ozmun JC, Gallahue DL. Motor development. Adapted Physical Education and Sport. $6^{\text {a }}$ ed. 2016; 375.

\section{Corresponding author}

*Diego Augusto Santos Silva

Federal University of Santa Catarina, Sports Centre, Research Center in Kinanthropometry and Human Performance, University Campus, Trindade, Postal code 88040-900, Florianopolis, Santa Catarina, Brazil.

Email: diegoaugustoss@yahoo.com.br

Manuscripted received on August 22, 2017

Manuscripted accepted on September 25, 2017

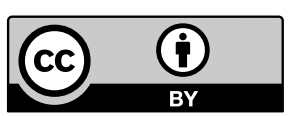

Motriz. The Journal of Physical Education. UNESP. Rio Claro, SP, Brazil - eISSN: 1980-6574 - under a license Creative Commons - Version 3.0 